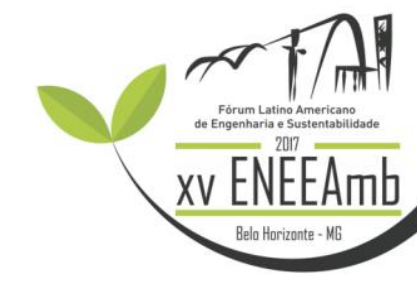

\title{
ANÁLISE DO ATENDIMENTO A LEGISLAÇÃO DE QUALIDADE DA ÁGUA NO SETOR SAÚDE DA UNIVERSIDADE FEDERAL DO PARÁ
}

Fábio Sergio Lima Brito - fabio.lima.ufpa@gmail.com

Universidade Federal do Pará

Juliana Maia Duarte - duartemaiajuliana@gmail.com

Universidade Federal do Pará

Ana Paula Gomes Mendonça - anapaulagomesmendonca03@gmail.com

Universidade Federal do Pará

Clara Cardoso Ferreira - clara_cardoso@ outlook.com.br

Universidade Federal do Pará

Rebeca Pina Nunes - rebeca.pina@ hotmail.com

Universidade Federal do Pará

Eduarda Izabelly Soares Ribeiro- eduardaizabelly@ hotmail.com

Universidade Federal do Pará 


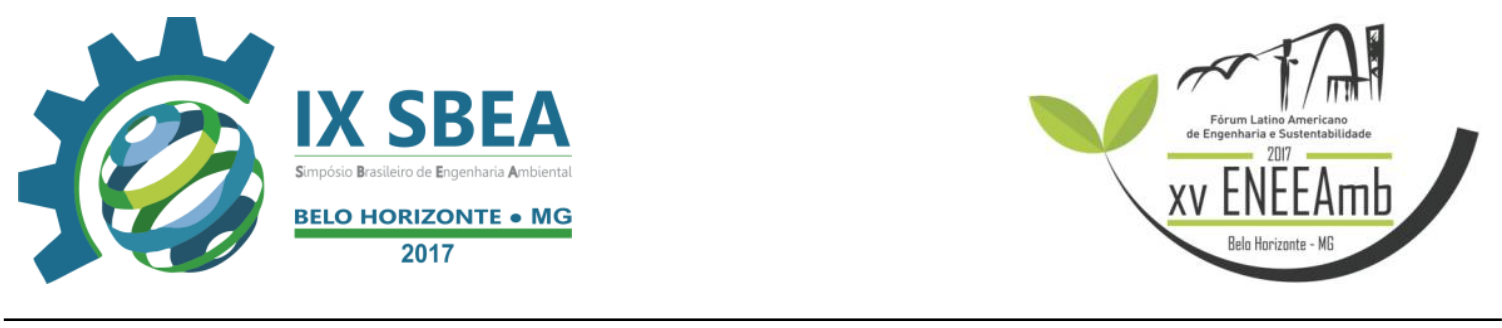

\section{RESUMO}

A água de abastecimento necessita de extrema atenção das autoridades sanitárias devido a importante relação que estabelece entre saúde pública e bem-estar. Nesse sentido, a Portaria 2.914 do Ministério da Saúde (MS) determina o padrão de potabilidade das águas distribuídas para o consumo humano. Por isso, o presente trabalho tem por objetivo analisar o atendimento a legislação de qualidade da água distribuída após seu tratamento no Setor Saúde da Universidade Federal do Pará. Os métodos de pesquisa compreendem: levantamento bibliográfico e análises laboratoriais com 25 pontos de coleta e amostragens, utilizando variáveis físico-químicas da água para, desta forma, comparar os dados obtidos com a legislação vigente do (MS). Os resultados apontaram que, a maioria dos pontos monitorados atenderam aos parâmetros determinados pela portaria, necessitando apenas de medidas corretivas como manutenção nas tubulações.

Palavras-chave: Água de Abastecimento, Análise Laboratoriais, Qualidade da Água.

\section{INTRODUÇÃO}

A água é um elemento essencial para manutenção da vida, sendo um recurso natural indispensável ao ser humano e aos demais seres vivos, além de ser suporte essencial aos ecossistemas (SOUZA, 2000).

“A água ao mesmo tempo que é tão importante para manutenção da vida ela pode também causar sérios problemas de saúde ao ser humano, pois quando não tratada corretamente veicula inúmeras doenças" (BATALHA, 2008).

Para tanto, a água utilizada para consumo humano deve passar por um processo de tratamento para torná-la potável assegurando que os diversos contaminantes (químicos ou biológicos) não ultrapassem o valor máximo permitido estabelecido pela legislação vigente (ARAÚJO, 2010).

Nessa perspectiva, para o funcionamento do Sistema de Abastecimento de Água (SAA) são realizadas várias etapas tais como: captação, adução, tratamento, reservação, redes de distribuição, estações elevatórias e ligações nos domicílios. 


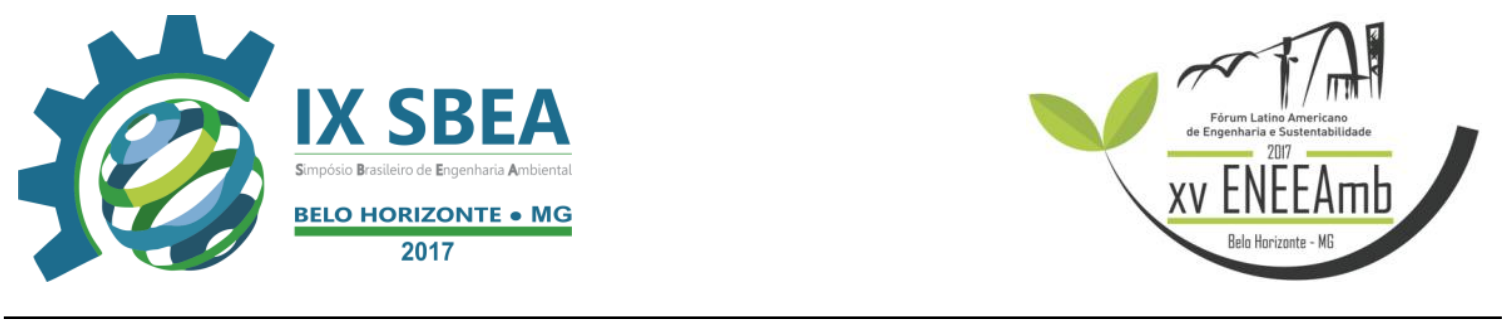

Após sua captação e tratamento, as águas naturais são destinadas ao consumo humano e são distribuídas às comunidades, e devem ser seguras do ponto de vista sanitário, isto é, não devem ser prejudiciais à saúde do consumidor (ZAVÁGLIO, 2013).

Nesse sentido, o abastecimento adequado de água é aquele que tem usos para consumo, preparo de alimentos, higiene pessoal e outros fins domésticos sem que ofereçam riscos à saúde pública e ao bem-estar dos usuários (LIMA, 2008).

Portanto, o presente trabalho tem por objetivo analisar a qualidade da água tratada que é distribuída no Setor Saúde da Universidade Federal do Pará, por intermédio de análises laboratoriais utilizando variáveis físico-químicas da água em cada ponto de coleta para, desta forma, comparar os dados obtidos com a portaria $\mathrm{n}^{\circ}$ 2.914 de 2011 do Ministério da Saúde (MS).

\section{MATERIAIS E MÉTODOS}

\subsection{Caracterização da Área de Estudo:}

A Cidade Universitária Prof. José da Silveira Netto- Universidade Federal do Pará, está localizada na cidade de Belém do Pará, às margens do Rio Guamá e ocupa uma área de 450 hectares, sendo dividida em quatro setores: Setor Básico (Campus I), Setor Profissional (Campus II), Setor Esportivo (Campus III) e Setor Saúde (Campus IV). Este estudo foi desenvolvido no Setor Saúde onde abriga vários prédios com uma grande circulação de pessoas.

\subsection{Determinação dos Pontos de Coleta:}

As coletas foram realizadas no Setor Saúde (SS) da UFPA sendo coletados 25 amostras, sendo escolhidos os prédios da Faculdade de Engenharia Naval (FENAV), Faculdade de Nutrição (FANUT) e Faculdade de Odontologia (FAO) e Faculdade de Medicina: Centro de Atenção e Saúde da Mulher e da Criança (CASMUC) conforme a figura 2. 


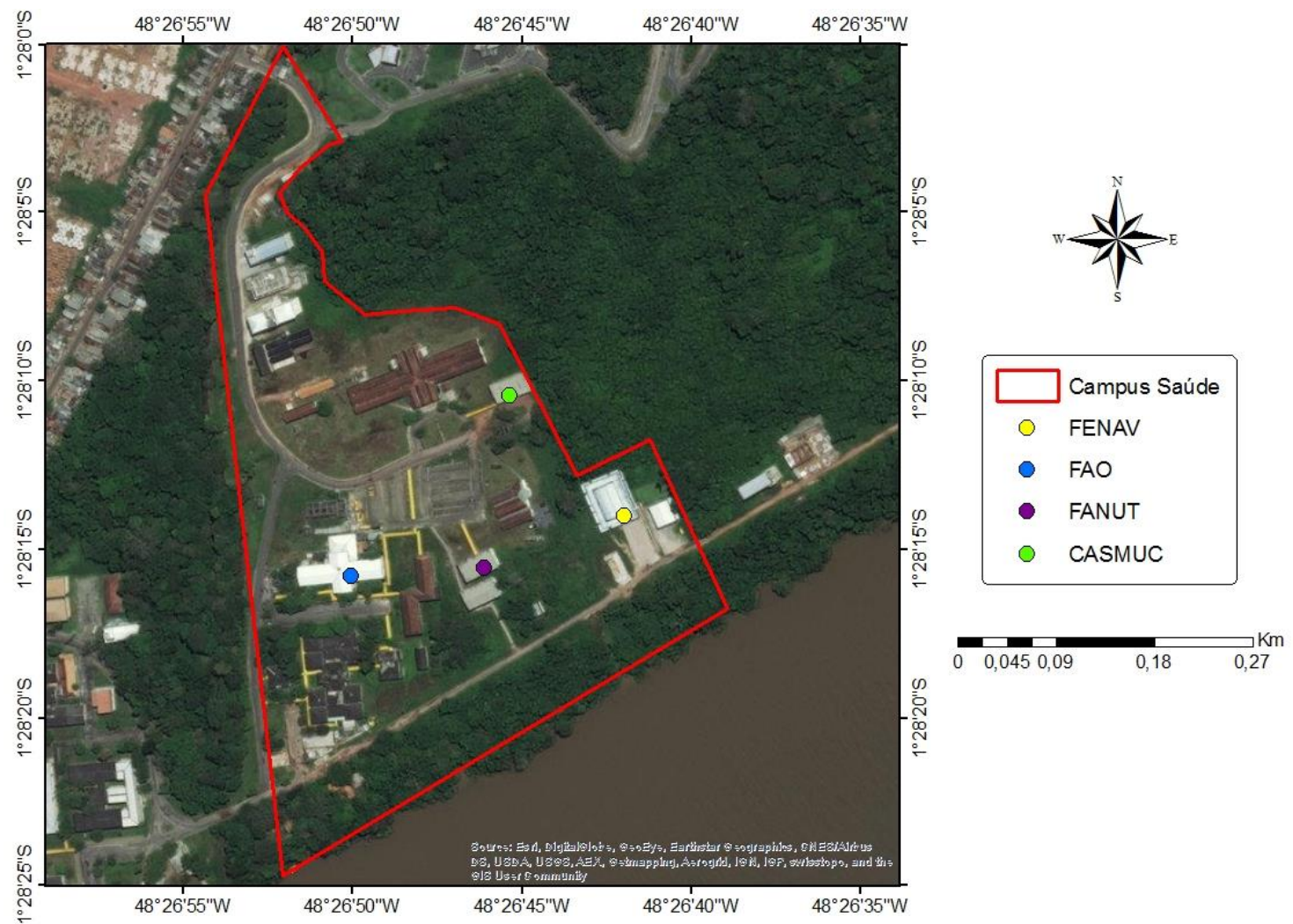

Figura 2. Localização dos pontos de coleta no Setor Saúde da UFPA

Nesse estudo, foram identificados e detalhados ainda os pontos de coleta, tipo de coleta e complemento com latitude e longitude para um diagnóstico mais completo da determinação dos pontos monitorados.

Tabela 1. Locais das coletas, pontos, tipo e complemento

\begin{tabular}{|c|c|c|c|}
\hline $\begin{array}{c}\text { Local da } \\
\text { Coleta }\end{array}$ & Pontos de coleta & Tipo de Coleta & Complemento \\
\hline CASMUC & Bebedouro & Simples & $1^{\circ} 46^{\prime} 96.45^{\prime \prime} \mathrm{S} ; 48^{\circ} 44^{\prime} 58.87^{\prime \prime} \mathrm{O}$ \\
\hline CASMUC & Torneira da Copa & Simples & $1^{\circ} 46^{\prime} 96.45^{\prime \prime} \mathrm{S} ; 48^{\circ} 44^{\prime} 58.87^{\prime \prime} \mathrm{O}$ \\
\hline CASMUC & Consultório 2 & Simples & $1^{\circ} 46^{\prime} 96.45^{\prime \prime} \mathrm{S} ; 48^{\circ} 44^{\prime} 58.87^{\prime \prime} \mathrm{O}$ \\
\hline CASMUC & Consultório 6 & Simples & $1^{\circ} 46^{\prime} 96.45^{\prime \prime} \mathrm{S} ; 48^{\circ} 44^{\prime} 58.87^{\prime \prime O}$ \\
\hline CASMUC & Banheiro FEM & Simples & $1^{\circ} 46^{\prime} 96.45^{\prime \prime} \mathrm{S} ; 48^{\circ} 44^{\prime} 58.87^{\prime \prime O}$ \\
\hline CASMUC & Banheiro MAS & Simples & $1^{\circ} 46^{\prime} 96.45^{\prime \prime} \mathrm{S} ; 48^{\circ} 44^{\prime} 58.87^{\prime \prime O}$ \\
\hline
\end{tabular}




\begin{tabular}{|c|c|c|c|}
\hline CASMUC & Torneira Externa & Simples & $1^{\circ} 46^{\prime} 96.45^{\prime \prime} \mathrm{S} ; 48^{\circ} 44^{\prime} 58.87^{\prime \prime O}$ \\
\hline FENAV & Bebedouro & Simples & $1^{\circ} 47^{\prime} 02.05^{\prime \prime} \mathrm{S} ; 48^{\circ} 44^{\prime} 49.63^{\prime \prime O}$ \\
\hline FENAV & Torneira da Copa & Simples & $1^{\circ} 47^{\prime} 02.05^{\prime \prime S} ; 48^{\circ} 44^{\prime} 49.63^{\prime \prime O}$ \\
\hline FENAV & Banheiro FEM & Simples & $1^{\circ} 47^{\prime} 02.05^{\prime \prime S} ; 48^{\circ} 44^{\prime} 49.63^{\prime \prime O}$ \\
\hline FENAV & Banheiro MAS & Simples & $1^{\circ} 47^{\prime} 02.05^{\prime \prime S} \mathrm{~S} 48^{\circ} 44^{\prime} 49.63^{\prime \prime O}$ \\
\hline FENAV & Banheiro PNE-MAS & Simples & $1^{\circ} 47^{\prime} 02.05^{\prime \prime S} \mathrm{~S} 48^{\circ} 44^{\prime} 49.63^{\prime \prime O}$ \\
\hline FENAV & Banheiro PNE-FEM & Simples & $1^{\circ} 47^{\prime} 02.05^{\prime \prime S} ; 48^{\circ} 44^{\prime} 49.63^{\prime \prime O}$ \\
\hline FANUT & Bebedouro & Simples & $1^{\circ} 28^{\prime} 14.96^{\prime \prime S} ; 48^{\circ} 26^{\prime} 46.24^{\prime \prime O}$ \\
\hline FANUT & Banheiro FEM & Simples & $1^{\circ} 28^{\prime} 14.96 " \mathrm{~S} ; 48^{\circ} 26^{\prime} 46.24^{\prime \prime O}$ \\
\hline FANUT & Banheiro MAS & Simples & $1^{\circ} 28^{\prime} 14.96 " \mathrm{~S} ; 48^{\circ} 26^{\prime} 46.24^{\prime \prime O}$ \\
\hline FANUT & Banheiro PNE-FEM & Simples & $1^{\circ} 28^{\prime} 14.96 " \mathrm{~S} ; 48^{\circ} 26^{\prime} 46.24^{\prime \prime O}$ \\
\hline FANUT & Banheiro PNE-MAS & Simples & $1^{\circ} 28^{\prime} 14.96 " \mathrm{~S} ; 48^{\circ} 26^{\prime} 46.24 " \mathrm{O}$ \\
\hline FANUT & Torneira Externa & Simples & $1^{\circ} 28^{\prime} 14.96^{\prime \prime S} ; 48^{\circ} 26^{\prime} 46.24^{\prime \prime O}$ \\
\hline FAO & Bebedouro & Simples & $1^{\circ} 28^{\prime} 15.8^{\prime \prime S} 48^{\circ} 26^{\prime} 50.3^{\prime \prime W}$ \\
\hline FAO & Consultório 1 & Simples & $1^{\circ} 28^{\prime} 15.8^{\prime \prime S} 48^{\circ} 26^{\prime} 50.3^{\prime \prime} \mathrm{W}$ \\
\hline FAO & Consultório 2 & Simples & $1^{\circ} 28^{\prime} 15.8^{\prime \prime S} 48^{\circ} 26^{\prime} 50.3^{\prime \prime} \mathrm{W}$ \\
\hline FAO & Banheiro FEM & Simples & $1^{\circ} 28^{\prime} 15.8^{\prime \prime S} 48^{\circ} 26^{\prime} 50.3^{\prime \prime W}$ \\
\hline FAO & Banheiro MAS & Simples & 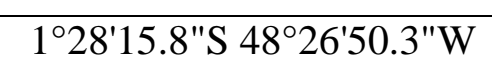 \\
\hline FAO & Torneira Externa & Simples & $1^{\circ} 28^{\prime} 15.8^{\prime \prime S} 48^{\circ} 26^{\prime} 50.3^{\prime \prime} \mathrm{W}$ \\
\hline
\end{tabular}

Fonte: Autores, 2017

\subsection{Coletas e Amostragem:}

As amostras foram coletadas em frascos de polietileno com tampa rosqueada e previamente esterilizados, cada um com capacidade de $300 \mathrm{ml}$ e devidamente etiquetadas para correta identificação. Logo após a coleta, as amostras foram encaminhadas para análises e determinações laboratoriais. Posteriormente, os dados foram comparados com a portaria 2.914 de 2011 do Ministério da Saúde (MS). Ademais, a Tabela 2 apresenta as variáveis e equipamentos utilizados: 


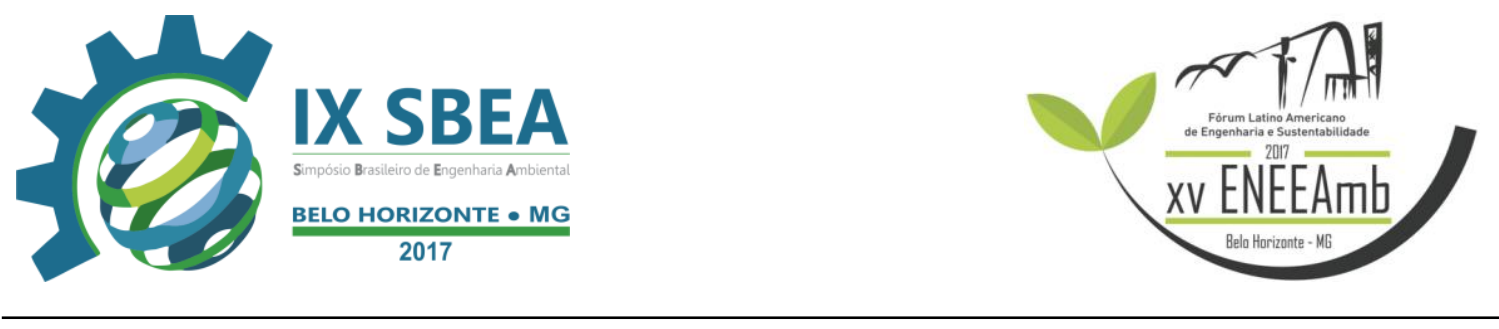

Tabela 2. Variáveis, Equipamentos e Descrição

\begin{tabular}{|c|c|c|}
\hline Variáveis & Equipamentos & Descrição \\
\hline PH & pH-metro PG 1800 Gehaka & $\begin{array}{c}\text { Mede a intensidade do caráter } \\
\text { ácido de uma solução }\end{array}$ \\
\hline Turbidez & Turbidimetro AP200 & Interferência na passagem da luz \\
\hline Cor Aparente & PolicontrolAquacolor Cor & Mede a intensidade de cor na \\
& Modelo INL-800CL. & água \\
\hline Cloro Residual & vede a quantidade de cloro \\
& residual na água \\
\hline Dureza Total & Espectrofotometro dr3900 & Mede a concentração de íons na \\
& água \\
\hline Nitrogênio & Espectrofotometro dr6000 & Mede a quantidade de nitrogênio \\
Amoniacal & na água \\
\hline Temperatura & Condutivímetro CG 1800 & Verifica a temperatura da amostra \\
& Gehaka & \\
\hline
\end{tabular}

Fonte: Autores, 2017

\subsection{Análise dos Dados:}

As análises foram feitas utilizando a estatística descritiva por meio de análise gráfica sendo utilizado o boxplot, cuja finalidade e descrever e resumir dados para melhor compreende-los. Em todos os cálculos foi utilizado o software Excel, usando a opção "Análise de dados".

\section{RESULTADOS E DISCUSSÃO}

Com as análises realizadas nos pontos de coleta do Setor Básico da Universidade Federal do Pará, foi possível diagnosticar a situação da qualidade da água nos prédios escolhidos para comparar com regulamentação vigente sobre o assunto: a Portaria $\mathrm{n}^{\circ}$ 2.914 de 2011 do Ministério da Saúde, a qual estabelece os padrões de potabilidade referente a qualidade da água para consumo humano e demais atividades que requerem o uso de água potável. 


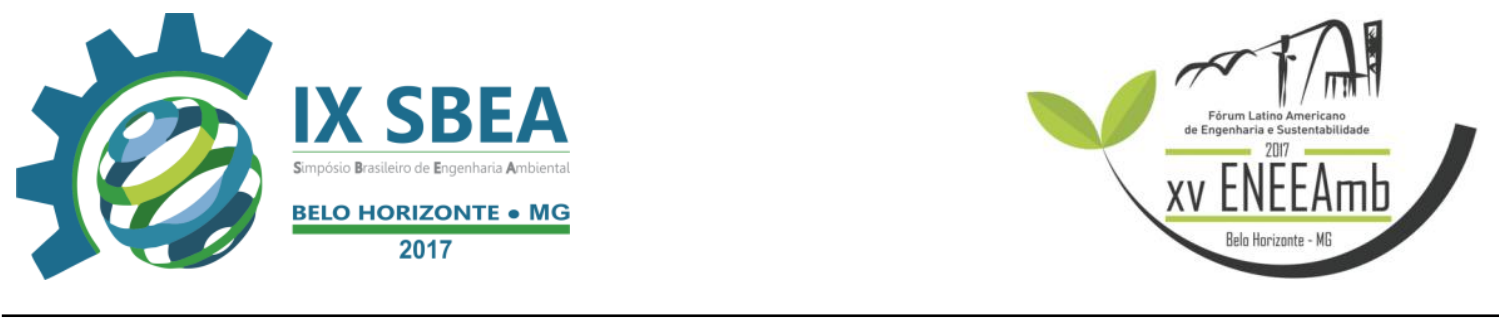

Sendo assim, no que se refere ao Ph das amostras coletadas pode-se constatar que $100 \%$ das amostras apresentaram valores na faixa de 6,0 a 9,5, ou seja, valores de acordo o exigido pela Portaria supracitada (Gráfico 1).

Outro parâmetro avaliado foi a turbidez que, serve para analisar a influência óptica de absorção e reflexão da luz de forma que se possa identificar as condições adequadas da água para consumo. Desse modo, os prédios da FENAV, FAO e FANUT apresentaram valores médios de: 3,38 (uT), 4,13 (uT) e 4,05 (uT) respectivamente, logo, estiverem dentro da legislação vigente. Já o prédio do CASMUC o valor médio foi de 7,07 (uT), sendo que o Valor Máximo Permitido (VMP) pela portaria 2.914 do MS é de 5 (uT).

Nesse sentido, é necessário investigar as possíveis causas e consequências desse acontecimento, nesses casos é possível inferir que: há pouca eficiência do tratamento de desinfecção do SAA havendo menos adição de cloro residual livre, bem como, falta de manutenção na tubulação do prédio do CASMUC pode ter causado a elevação da turbidez na água. Esse diagnóstico se faz necessário, pois o referido prédio atende diariamente uma demanda muito grande de crianças e mulheres (Gráfico 2).

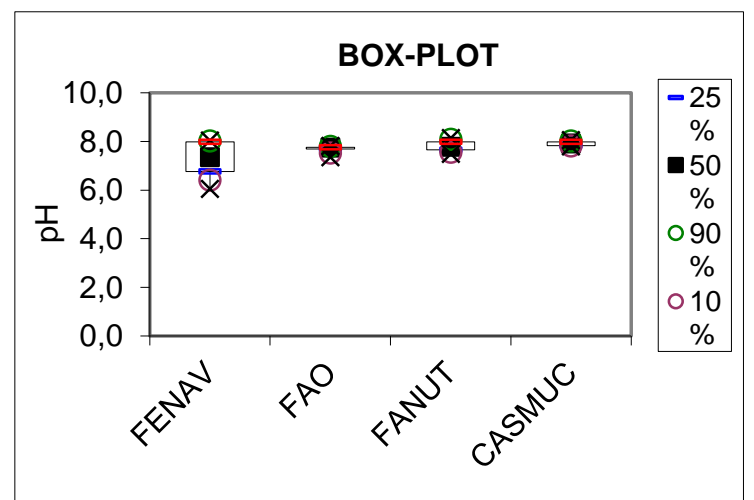

Gráfico 1. Análise do Ph no Setor Saúde

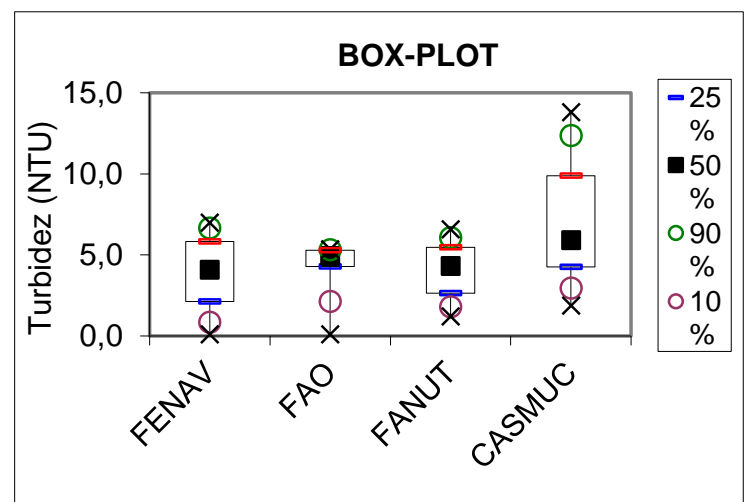

Gráfico 2. Análise da Turbidez nos Setor Saúde

Outra variável importante para o diagnóstico deste estudo foi a cor, cuja a finalidade é medir a sua intensidade na água, que geralmente, indica a presença de metais como ferro $(\mathrm{Fe})$ e manganês $(\mathrm{Mn})$. Nessa perspectiva, todos os prédios estudados 
estiveram com valores acima de 15 UNT, sendo em média 16, 77 na FENAV, 23,72 na FAO, 25, 28 na FANUT e 27,05 no prédio CASMUC (Gráfico 3).

Com relação ao cloro livre residual a legislação estabelece o valor máximo permitido de $2 \mathrm{mg} / \mathrm{L}$ e mínimo de $0,2 \mathrm{mg} / \mathrm{L}$. Com isso, todos os prédios apresentaram-se dentro dos padrões estabelecidos pela regulamentação vigente, pois as médias foram de 0,50 mg/L (Gráfico 4).

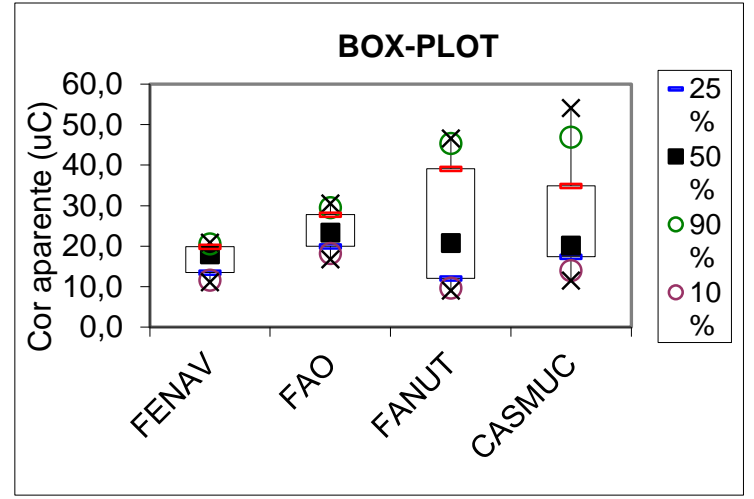

Gráfico 3. Análise de cor aparente no Setor Saúde

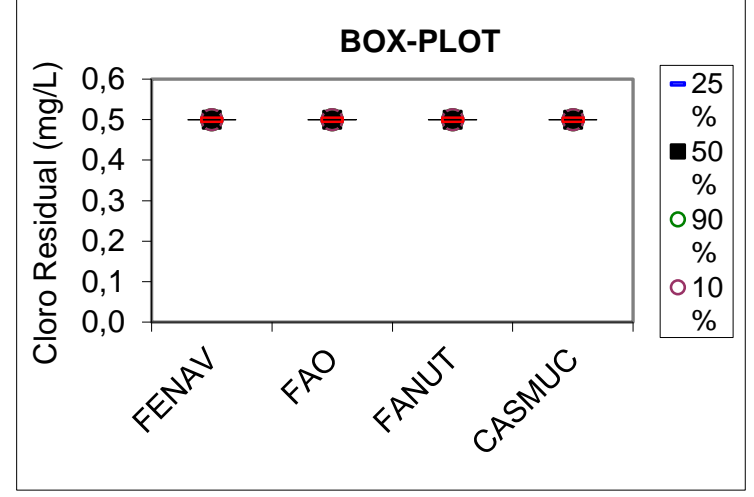

Gráfico 4. Análise de cloro residual livre no Setor Saúde

O gráfico 5 apresenta a dureza total das águas distribuídas nos locais estudos, em que foi constatado a média de 0,06 para FENAV de 0,05 para os prédios do CASMUC e FANUT, e de 0,34 para o FAO. Em determinadas concentrações a dureza causa sabor desagradável na água. No entanto, as amostras tiveram valores inferiores a 45 $\mathrm{mg} / \mathrm{CaCO} 3$ caracterizando-se assim como uma água extremamente macia conforme a portaria 2.914.

Nesse seguimento, para o Nitrogênio Amoniacal as médias foram de 0,06 (mg/L) para o FENAV, FAO e CASMUC, enquanto para FANUT o valor encontrado foi de 0,23 (mg/L), estando dentro do permitido pela regulamentação de qualidade da água (Gráfico 6).

O termo nitrogênio amoniacal abrange ainda as concentrações das formas do nitrogênio como amônia (NH3), forma não ionizada e como amônio (NH4+), forma ionizada (APHA; AWWA; WPCF, 1995). 


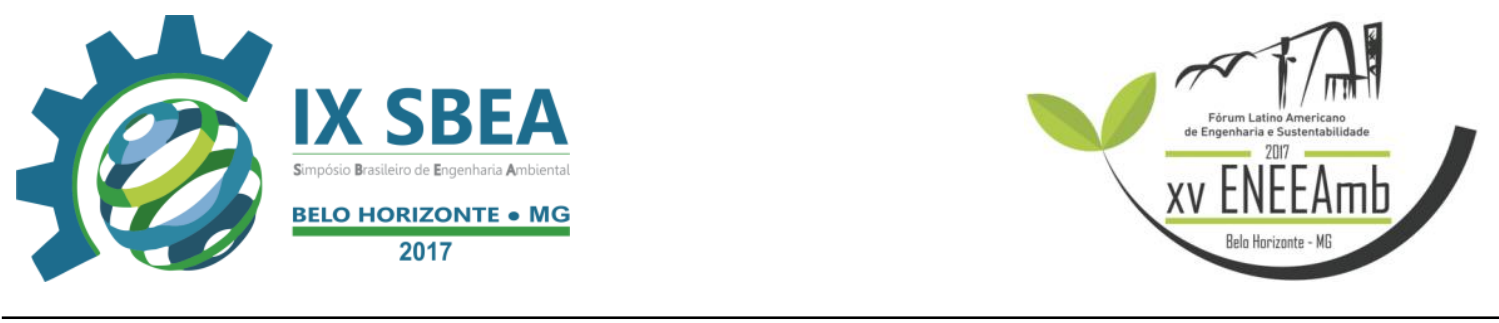

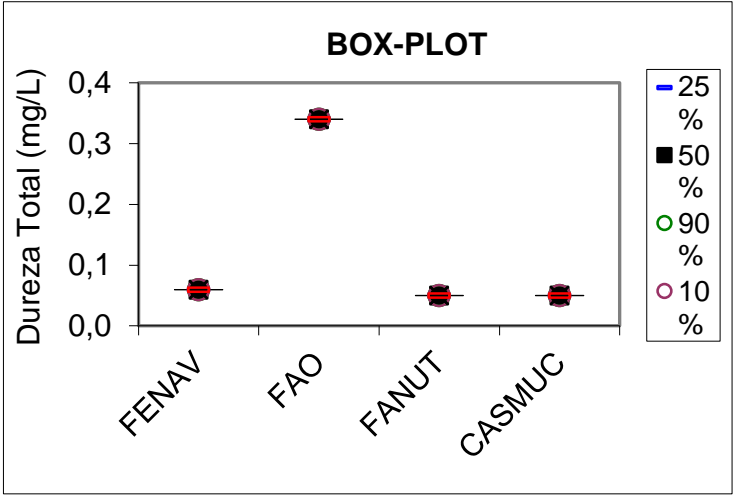

Gráfico 5. Análise da dureza total no Setor Saúde

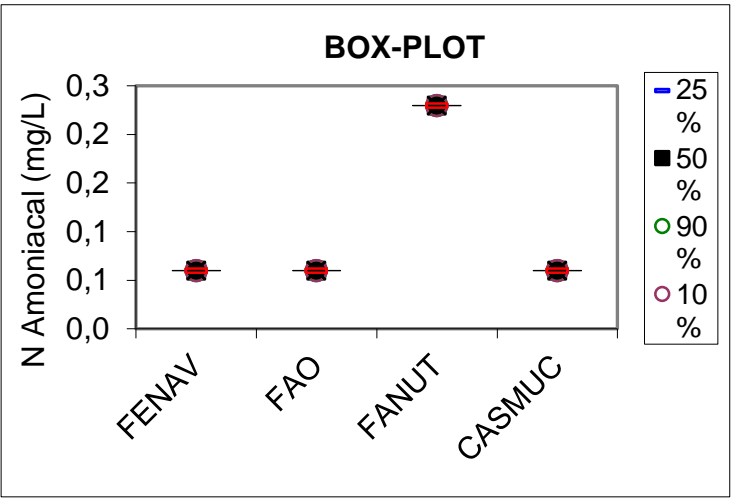

Gráfico 6. Análise do nitrogênio amoniacal no Setor Saúde

Por último, foi analisado a temperatura das águas distribuídas, embora este não seja um parâmetro de qualidade da água, essa variável foi verificada para medir o conforto térmico das águas disponibilizada para consumo e demais atividades como banho, cozinhar e lavar alimentos. Dessa forma, todas as amostras estavam em temperatura ambiente entre $27,15 \mathrm{C}^{\circ}$ a $28,22 \mathrm{C}^{\circ}$, o que se torna desagradável para consumo e banho (Gráfico 7).

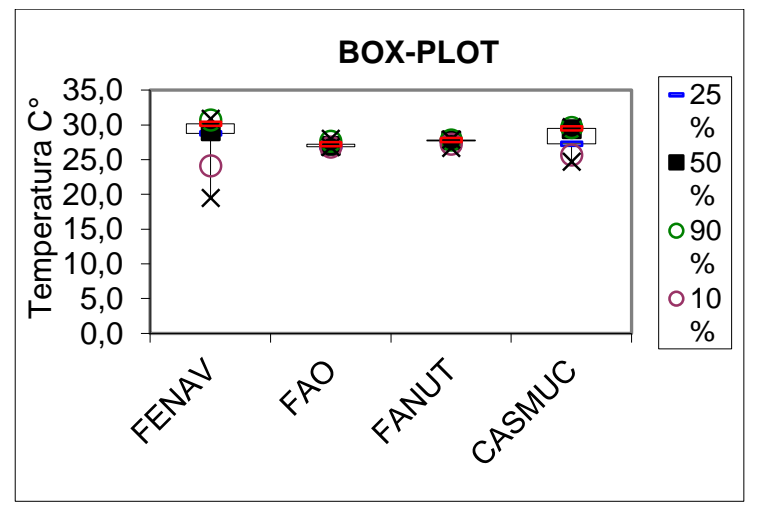

Gráfico 7. Análise da temperatura no Setor Saúde

\section{CONCLUSÕES/RECOMENDAÇÕES}

Neste estudo foi possível diagnosticar a qualidade da água tratada e distribuída a fornecida ao Setor Básico da Universidade Federal do Pará. Os resultados obtidos a partir das variáveis físico-químicas atendem a maioria dos parâmetros estabelecidos pela regulamentação vigente (Portaria 2.914 de 2011 do Ministério da Saúde). 


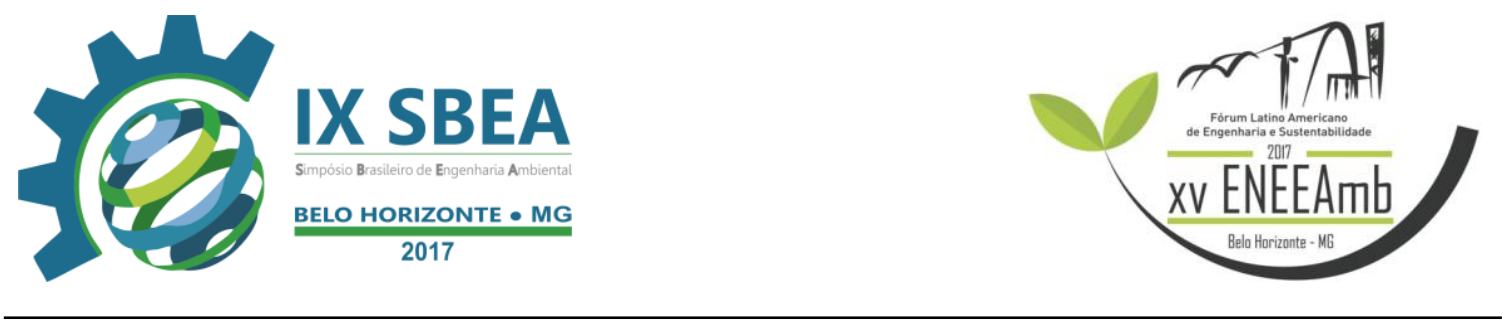

No entanto, alguns pontos de coleta apresentaram-se fora dos padrões de potabilidade permitida pela legislação como os do prédio do CASMUC que apresentou as maiores irregularidades necessitando assim de medidas corretivas em cárter de urgência.

De forma geral as variáveis de turbidez e cor apresentaram-se fora do recomendado pela portaria supracitada. Por isso, faz se necessário um acompanhamento constante dos pontos de amostragem por meio de um efetivo monitoramento para avaliar as águas que abastecem a UFPA.

Por fim, recomenda-se, a implantação de ações paliativas para o gerenciamento das águas tratadas na instituição como: manutenção constante na tubulação que é bastante antiga na universidade, troca dos filtros no caso dos bebedouros e verificação do funcionamento dos mesmos.

Adotando essas medidas a curto prazo e efetivando o plano de amostragens a problemática de qualidade da água pode ser mitigada de forma mais eficiente com contribuição da alta administração investindo e incentivando em pesquisas futuras para mais análises, objetivando o aperfeiçoamento da presente proposta.

\section{REFERÊNCIAS BIBLIOGRÁFICAS}

APHA; AWWA; WPCF. Standard methods for the examination of water and wastewater. 19th ed. Washington D.C.: American Public Health Association, 1995. $953 p$.

ARAÚJO, M. C. S. P. Indicadores de vigilância da qualidade da água de abastecimento da cidade de areia (PB). Campina Grande, 110 p., 2010. Dissertação (Mestrado) -Universidade Federal de Campina Grande.

BATAlHA, B. H. L.; Água para Consumo Humano. 2008. Disponível em: <http://www.consultoriaambiental.com.br >. Acesso em: 24 de abril. 2012.

LIMA, C.S.R. Água de abastecimento público no município de recife-PE - uma revisão. Recife, 57 p., 2008. Monografia (Especialização) - Universidade Federal Rural do Semiárido.

MACÊDO JAB. Águas \& águas. Belo Horizonte: CRQMG, 2007. 1027p. 


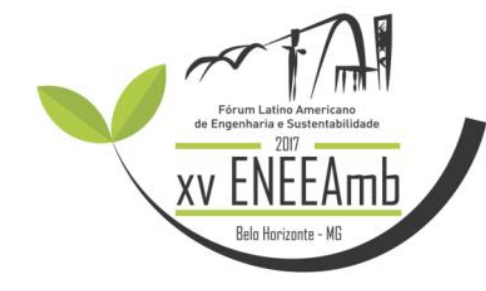

SOUZA, D. A. Desenvolvimento de metodologia analítica para determinação de multiresíduos de pesticidas em águas de abastecimento de São Carlos - SP. 52 2000. 109f. Dissertação (Doutorado em Ciências da Engenharia Ambiental). Escola de Engenharia de São Carlos, Universidade de São Paulo.

ZAVÁGLIO, P. S. Avaliação da qualidade da água no sistema de abastecimento da cidade de santa lúcia - SP. Trabalho de Conclusão de Curso. Universidade Estadual Paulista - UNESP, Araraquara, 2013. 